\title{
A STUDY OF FACTORS AFFECTING A COMBUSTION METHOD FOR DETERMINING CARBON IN LITHIUM HYDRIDE
}

R. E. Barringer

R. E. Thornton

\section{OAK RIDGE Y-12 PLANT} OAK RIDGE. TENNESSEE

prepared for the U.S. ENERGY RESEARCH AND DEVELOPMENT ADMINISTRATION under U.S. GOVERNMENT Contract W-7405 eng 26 


\section{DISCLAIMER}

This report was prepared as an account of work sponsored by an agency of the United States Government. Neither the United States Government nor any agency Thereof, nor any of their employees, makes any warranty, express or implied, or assumes any legal liability or responsibility for the accuracy, completeness, or usefulness of any information, apparatus, product, or process disclosed, or represents that its use would not infringe privately owned rights. Reference herein to any specific commercial product, process, or service by trade name, trademark, manufacturer, or otherwise does not necessarily constitute or imply its endorsement, recommendation, or favoring by the United States Government or any agency thereof. The views and opinions of authors expressed herein do not necessarily state or reflect those of the United States Government or any agency thereof. 


\section{DISCLAIMER}

Portions of this document may be illegible in electronic image products. Images are produced from the best available original document. 
Reference to a company or product name does not imply approval or recommendation of the product by Union Carbide Corporation or the U.S. Energy Research and Development Administration to the exclusion of others that may meet specifications.

\section{Printed in the United States of America. Available from National Technical Intormatıon Service \\ U.S. Department of Commerce 5285 Port Royal Road, Springfield, Virginia 22161 \\ Price: Printed Copy \$4.00; Microfiche $\$ 2.25$}

This report was prepared as an account of work sponsored by the United States Government. Neither the United States nor the Energy Research and Development Administration, nor any of their employees, nor any of their contractors, subcontractors, or their employees, makes any warranty, express or implied, or assumes any legal liability or responsibility for the accuracy, completeness or usefulness of any information, apparatus, product or process disclosed, or represents that its use would not infringe privately owned rights. 
Date of Issue: September 19, 1975

Distribution Category: UC-4

\title{
A STUDY OF FACTORS AFFECTING A COMBUSTION METHOD FOR DETERMINING CARBON IN LITHIUM HYDRIDE
}

\author{
R. E. Barringer \\ Laboratory Development Department \\ $Y-12$ Development Division \\ R. E. Thornton \\ Y-12 Plant Laboratory \\ Product Certification Division
}

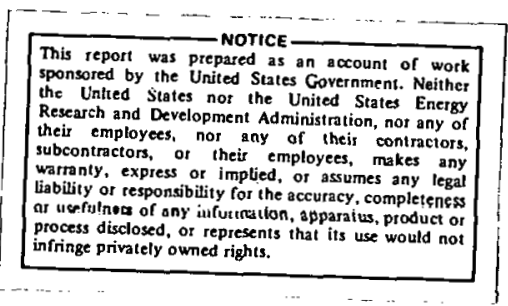

Oak Ridge Y-12 Plant

P. O. Box Y, Oak Ridge, Tennessee 37830

Prepared for the US Energy Research and Development Administration

Under US Government Contract W-7405-eng-26 


\section{ABSTRACT}

An investigation has been made of the factors affecting a combustion method for the determination of low levels ( 300 to 15000 micrograms/gram) of carbon in highly reactive lithium hydride. Optimization of the procedure with available equipment yielded recoveries of $90 \%$, with a limit of error $(0.95)$ of $\pm 39 \%$ relative tor alıquants containing 35 to 55 micrograms of carbon $(500$ to 800 micrograms of carbon per gram of lithium hydride sample). Sample preparation, thermal decomposition of the hydride, final ignition of the carbon, and carbon-measurement steps were studied, and a detailed procedure was developed. 


\section{CONTENTS}

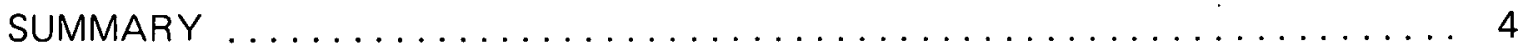

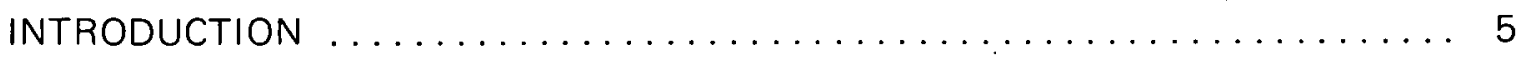

FACTORS AFFECTING THE COMBUSION METHOD FOR DETERMINING

CARBON IN LITHIUM HYDRIDE ............. 6

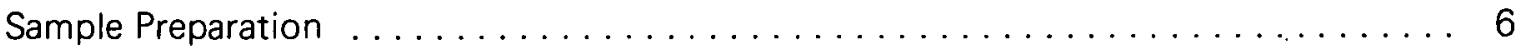

Homogeneity of the Samples ........................... 6

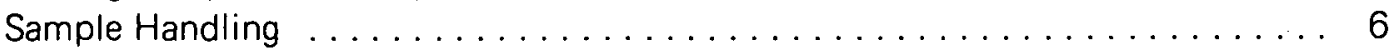

Choice of Sample Capsule .......................... 6

Thermal Decomposition of the Hydride $\ldots \ldots \ldots \ldots \ldots \ldots \ldots \ldots \ldots \ldots \ldots$

Choice of Furnaces ............................. 6

Control of the Helium Gas Flow $\ldots \ldots \ldots \ldots \ldots \ldots \ldots \ldots \ldots \ldots \ldots$

Final Ignition of the Carbon ......................... 7

Choice of the Combustion Crucible and Cover . . . . . . . . . . . . . . 7

Combustion Conditions ............................ 7

Carbon Measurement .................................... 8

Purification and Conversion of the Combustion Gases .............. 8

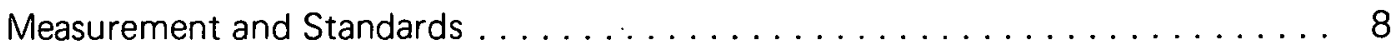

Results .................................... 9

Recovery from the Spiked Samples $\ldots \ldots \ldots \ldots \ldots \ldots \ldots \ldots \ldots \ldots \ldots$

Precision of the Analyses $\ldots \ldots \ldots \ldots \ldots \ldots \ldots \ldots \ldots \ldots \ldots \ldots$

Comparison of Carbon Results from Hydride and Metals . . . . . . . . . . . 10

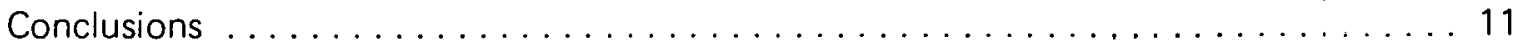

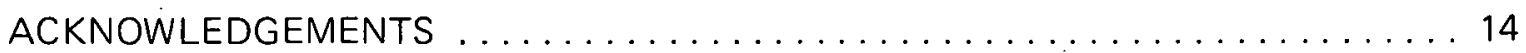

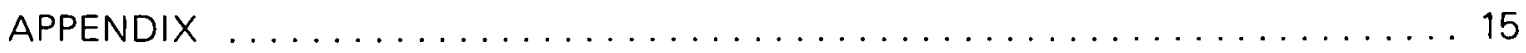

Detailed Revised Procedure for Determining Low Carbon in Lithium

Hydride or Deuteride .................. 15 


\section{SUMMARY}

Improved precision and accuracy of the results obtained for carbon in lithium hydride by a combustion method were achieved following an investigation of the factors affecting the analyses. Many aspects of the method were examined, including sample preparation, sample decomposition, sample combustion, measurement of carbon, recovery from spiked samples, and long-term precision of the analyses. Details such as sample handling, the sample container, the combustion crucible, control of temperatures, and control of times of heating were optimized for best results with the highly reactive lithium hydride material. The carbon standards used and manner of calibration of the combustion analyzer instrument were altered to optimum conditions.

Recoveries by the suggested procedure were $90 \%$. Long-terlm piecisiulis of results wcrc improved from an average limit of error (0.95) for a single measurement of $\pm 94 \%$ of the mean to $\pm 39 \%$ of the mean. The usetul range of the suggested pructuluie is 200 to 15000 micrograms of carbon per gram of lithium hydride sample. A detailed procedure has been developed. 


\section{INTRODUCTION}

This investigation, conducted at the Oak Ridge $Y-12$ Plant, (a) was prompted by wide variations in the precision of results routinely obtained from the oxygen-atmosphere combustion method for carbon in lithium hydride.

Typical results from replicate analyses on several batches of lithium hydride are given in Table 1. Analyses on each batch were performed over a period of several weeks. The average limit of error for a single determination was $\pm 94 \%$ of the mean, which is much higher than desirable.

Table 1

TYPICAL RESULTS FOR CARBON IN LITHIUM HYDRIDE BY THE EXISTING PROCEDURE

\begin{tabular}{|c|c|c|c|c|c|c|}
\hline \multirow[b]{2}{*}{ Batch } & \multirow{2}{*}{$\begin{array}{l}\text { Number of } \\
\text { Replicates }\end{array}$} & \multirow{2}{*}{$\begin{array}{c}\text { Mean } \\
\text { Value } \\
(\mu \mathrm{g} C / \mathrm{g})\end{array}$} & \multicolumn{4}{|c|}{ Limits of Error $(0.95)$ on a Single Analysis } \\
\hline & & & $\overline{(\mu \mathrm{g} \mathrm{C} / \mathrm{g})}$ & & (\% of & mean) \\
\hline 2 & 34 & 1922 & \pm 1679 & & & 87 \\
\hline 3 & 44 & 1148 & \pm 1479 & & & 29 \\
\hline 4 & 15 & 2333 & \pm 1747 & & \pm & 75 \\
\hline \multirow[t]{2}{*}{5} & 48 & 950 & \pm 831 & & \pm & 87 \\
\hline & & & & Average & \pm & 94 \\
\hline
\end{tabular}

The speed, ease, and consequent relatively low cost of the existing method utilizing a Laboratory Equipment Company (LECO) carbon analyzer merited attempted refinements rather than selection of a method of greater complexity. The oxygen-combustion method, using a LECO instrumerit, consists of several steps: A preheat step in a helium atmosphere thermally decomposes the lithium hydride, releasing hydrogen which is swept away by the helium flow. (Ignition of the hydride with oxygen before removal of the hydrogen would result in an explosive reaction which would, as a minimum effect, cause the sample to spatter.) Ignition with an oxygen sweep then burns the carbon to the monoxide or dioxide. Heat at this stage should be sufficient to decompose any carbonate present, liberating carbon dioxide. The combustion yases pass through hot manganese dioxide or copper oxide to convert any monoxide present to the dioxide. After being trapped in a molecular sieve at room temperature, the dioxide is released by heating the molecular sieve trap. A helium sweep passes the carbon dioxide and oxygen through a silica-gel separation column and into a thermal-conductivity detector, the signal from which is integrated over the time the dioxide is detected. A digital readout of the integrated signal displays the micrograms of carbon detected. Factors investigated for possible improvement were those influencing sample preparation, thermal decomposition of the hydride, final ignition of the carbon, and carbon measurement.

(a) Operated by the Union Carbide Corporation's Nuclear Division for the US Energy Research and Development Administration. 


\section{FACTORS AFFECTING THE COMBUSTION METHOD FOR DETERMINING CARBON IN LITHIUM HYDRIDE}

\section{SAMPLE PREPARATION}

\section{Homugeneity of the Samplos}

All batches of lithium hydride listed in Table 1 were ground and given a thorough mechanical blending. The likelihood of accounting for the wide limits of error shown in Table 1 because of inhomogeneity is remote.

\section{Sample Haridling}

All samples were stored and transferred in an argon-purged dry box. Herte, llansfer of the sample was made to a weighed metal capsule which was sealed by flattening and rolling the end. The sealed capsule was then placed into a plastic vial which was capped, trapping a dry argon atmosphere with the sample capsule. After obtaining a gross weight on the capsule, the samples were stored in sealed vials in the argon dry box until analyzed. Nothing in the handling procedures accounted for the wide variation in results.

\section{Choice of Sample Capsule}

Two types of sample capsules were tried. One was a commercially available tin capsule $(5 \times$ $20 \mathrm{~mm})$, supplied by LECO. Another capsule was locally prepared from aluminum foil [0.038 $\mathrm{mm}$ (1 1/2 mils) thick], by rolling the foil around a 6-mm-diameter rod and sealing one end by flattening and rolling. A significantly higher blank obtained with the aluminum capsules plus the danger of trace carbon contamination during the hand-forming process led to the choice of the commercial tin capsule. However, one disadvantage of the tin capsule was the limited sample which could be used due to its physical size. An average sample weight routinely used was only 0.07 gram of lithium hydride.

\section{THERMAL DECOMPOSITION OF THE HYDRIDE}

\section{Choice of Furnaces}

It was necessary to decompose the lithium hydride and remove the hydrogen before ignition with oxygen; otherwise, an explosion would occur with the mixture of oxygen and liberated hydrogen. The decomposition step was originally performed in a separate LECO induction furnace at a reduced temperdture; then, after cooling, the siminle was transforred to a second furnace for final ignition with oxygen. The extra handling was undesirable and also the highly reactive residue could pick up carbon dioxide from the room atmosphere.

A two-stage single-furnace procedure replaced the previously used two-furnace setup. An initial mild heating with a helium sweep decomposed the lithium hydride and carried away the hydrogen. A moderate temperature was adequate for decomposing the lithium hydride which has a dissociation pressure of $760 \mathrm{~mm}$ of mercury at $850^{\circ} \mathrm{C}$.

Final combustion of the carbon was performed in the same induction furnace with an oxygen atmosphere at elevated temperatures. 


\section{C.ontrol of the Helium Gas Flow}

Monitoring of the helium flow during the decomposition step was accomplished by the installation of a flowmeter of the floating-ball type. The available flowmeter was calibrated for air in standard cubic feet per hour (scfh). A setting of 1 scfh provided sufficient helium flow to sweep the liberated hydrogen from the furnace during a two-minute decomposition step and protect the lithium residue from further reaction. When used with helium, the flow was approximately $20 \%$ greater than that indicated for air. Simple and fast changing from a helium to an oxygen sweep was provided by the installation of an electrically operated valving system.

\section{FINAL IGNITION OF THE CARBON}

\section{Choice of the Combustion Crucible and Cover}

The lithium greatly attacked a standard LECO combustion crucible during the high-temperature oxygen combustion step. Sometimes the molten sample penetrated completely through the crucible wall and fused to the furnace wall or furnace pedestal. Changing to the "green" LECO high-temperature crucible reduced the fusion penetration into the crucible; but, on occasion, penetration completely through the "green" crucible wall still occurred.

Two solutions to the crucible fusion problem were tried-Placing a piece of crucible cover in the bottom of the crucible under the sample and accelerators to reduce the penetration. Also, better control of crucible penetration was achieved by uniformly covering the bottom of the crucible with a granular sand obtained by grinding porous crucible covers. The sand held the lithium during combustion, reducing crucible penetration to a workable level.

In routine carbon analyses with the LECO instrument, a crucible cover with a center hole provided for the rapid escape of combustion gases. However, considerable spattering occurred through the cover hole onto the furnace walls when lithium hydride samples were ignited. Also, material falling from the furnace walls onto the sample crucible often gave high carbon values. A LECO porous crucible cover without a central hole prevented spatter onto the furnace walls, but much material collected on the bottom of the cover, plugging some of the cover and preventing a complete flow of the combustion gases. A disc of aluminum foil, with a diameter the same as that of the cover [cut from $0.038-\mathrm{mm}$ (1 1/2-mil) sheet] was placed under the cover. Heat from the oxygen combustion step melted away the aluminum foil. Spatter of sample onto and consequent plugging of the porous cover was minimized. No interference was observed with hydrogen removal in the decomposition step or with recovery of carbonaceous gases emanating from the sample during the combustion step. Thurough cleaning of the aluminum toil discs in. Freon. 113 solvent removed any contamination resulting from the disc-cutting procedure.

\section{Combustion Conditions}

Complete combustion and removal of the carbon from lithium hydride samples requires a high temperature. Most of the carbon contamination present in lithium hydride, as received in the Y-12 Plant Laboratory, was believed to be present as the carbonate. Temperatures 
above $1310^{\circ} \mathrm{C}$ (the temperature at which the dissociation pressure of lithium carbonate reaches atmospheric) are indicated for recovery of the carbon.

Metallic substances, called "accelerators" or "concentrators", are used in induction furnaces to aid in heat generation when the sample itself will not produce sufficient heat. Tin, copper, and iron powders or granules are common accelerators used with carbon analyses. Tin is somewhat volatile at the high temperatures achieved and deposits on the crucible lid. Of several combinations of accelerators tried, the best for maximum heat and minimum spattering was two grams of granular copper and 0.7 gram of iron powder. The induction furnace of the instrument used in these experiments reached a plate current in excess of 400 milliamperes with this amount of accelerator. Incomplete combustion and removal of carhon was experienced whenever the plate current. fell below 350 milliamperes. The temperature attained was estimated at $15000^{\circ} \mathrm{C}$.

A four-minute combustion period was necessary to insure complete recovery of the carbon from lithium hydride. Automatic timing of the combustion period was accomplished by the addition of a two-minute timer in the circuit of the LECO analyzer which could not time for the full four-minute period. The external timer controlled two minutes of combustion time, then switched to the analyzer unit for the last two minutes.

An oxygen gas flow of two liters per minute was adequate to complete the combustion and to sweep the combustion-produced gases from the furnace to the analyzer within four minutes.

\section{CARBON MEASUREMENT}

\section{Purification and Conversion of the Combustion Gases}

The oxygen gas swept the combustlon yases frum llit furince successively' through a duet. trap, a room-temperature manganese dioxide trap for trapping sulfur gases which would interfere, a heated manganese dioxide or a heated cupric oxide trap for converting any carbon monoxide to dioxide, a magnesium perchlorate desiccant for removing moisture, and finally a molecular sieve trap where the carbon dioxide was held. Daily changing of the manganese dioxide (heated reactor) and the magnesium perchlorate desiccant was required when using the apparatus for lithium hydride samples. Rapid exhaustion of these components results when hydrogen, liberated during the decomposition step, is converted to water by the manganese dioxide and subsequently absorbed in the desiccant.

\section{Measurement and Standards}

Heating the molecular sieve trap released the carbon dioxide which was swept by helium through a silica gel chromatographic column and through a thermocouple detector. The integrated detector signal was displayed on the analyzer as micrograms of carbon.

Two carbon standards were used for instrument calibrations, both National Bureau of Standards steel samples (Sample 166b containing 190 micrograms of carbon per gram and Sample $32 \mathrm{e}$ containing 4090 micrograms carbon per gram). Approximately 0.1 gram of standard was placed in a combustion crucible with the ground crucible cover material, 
accelerators, and tin capsule, and covered with the aluminum disc and porous cover. The low-concentration control of the analyzer. unit was set so the readout was at the theoretical amount of carbon (approximately 19 micrograms) corresponding to the weight of low standard used. The upper concentration control or slope was set likewise from the high standard at approximately 409 micrograms carbon. A second standard was expected to check within \pm 3 micrograms of carbon at the low concentration and \pm 10 micrograms of carbon at the 400-microgram carbon level.

Practice up to this time was to run a blank without the sample for the low reading, but better results were achieved when a low-carbon standard was substituted for setting the low readings. Without the lithium present, the blank did not reach as high a temperature upon combustion as did the samples. Substituting an iron standard for lithium permitted the attainment of the proper combustion temperature.

\section{RESULTS}

\section{Recovery from the Spiked Samples}

A ground lithium hydride batch was spiked with carbon by adding a weighed amount of lithium carbonate in a dry-argon-atmosphere glove box. Thorough mixing on a Spex mixer-mill in a mortar with copper gaskets rather than the customary cork gaskets provided a sample containing 526 micrograms per gram more carbon than in the original batch. The original lithium hydride batch and the spiked batch were analyzed repetitively on three different days. The results are listed in Table 2. The high result (1820 micrograms of carbon per gram) obtained on the spiked batch on Day 2 was suspect, perhaps indicating contamination. Applying Grubbs test, $(b)$ this high value is considered an outlier at the $98 \%$ confidence level.

Omitting the Day 2 result, the average recovery was 471 micrograms of carbon, or $90 \%$ based on the difference between the mean of the original and spiked batches. This recovery was considered acceptable for the method and sample type. Statistical analysis of variance showed no significant differences in the means of results obtained on different days. The standard deviation for the original batch was 67 micrograms of carbon per gram, with a limit of error. 10.95$)$ for a single determination of \pm 147 micrograms of carbon per gram, or $\pm 18.7 \%$ relative to the mean. The standard deviation for the spiked batch was 196 micrograms of carbon per gram, with a limit of error $(0.95)$ for a single determination of \pm 431 micrograms of carbon per gram, or $\pm 33 \%$ relative to the mean.

\section{Precision of the Analyses}

Routine results of the method were collected on two batches of ground, thoroughly mixed lithium hydride. Samples of the control batches were unidentified and submitted routinely.

(b) Grubbs, Frank E. and Beck, Glenn; "Extension of Sample Sizes and Percentage Points for Significance Tests of Outlying Observations", Technometrics, 14, p 847 (1972). 
Analyses in duplicate were performed, usually on one sample per day; but, sometimes, two or more samples were run on the same day. The second control batch was submitted only after the first was used up. Samples from the two batches were submitted over a time span of one year. The two individual and mean results for each sample are listed in Table 3.

Statistical analysis of the variance showed a significant difference in the results run on different days. This phenomenon was believed due, in part, to the difficulty in reproducibly setting the analyzing section to the true value of the standards. An error of \pm 3 micrograms of carbon in setting to the lower standards would shift all results on a 0.07 -gram lithium hydride aliquant by \pm 43 micrograms of carbon per gram of sample. For Batch 8 , the standard deviation within an analysis comprising two results was 69 micrograms of carbon per gram, whereas the overall standard deviation was 116 micrograms. The overall limit of error (0.95) for a single determination of Batch 8 was \pm 231 micrograms of carbon per gram, or $\pm 44 \%$ of the mean value. Corresponding statistical data for Batch 9. were a standard deviatinn within an analysis of 83 micrograms of carbon per gram, an overall deviation of 135 micrograms of carbon per gram, and an overall limit of error (0.95) for a single determination of \pm 268 micrograms of carbon per gram, or $\pm 34 \%$ of the mean value. These long-term results represent the routine capabilities of the revised procedure.

The average limit of error of $\pm 39 \%$ for a single determination, as shown by these long-term results, is a significant improvement over the $\pm 94 \%$ experienced previously.

Table 2

RECOVERY OF CARBON SPIKES

\begin{tabular}{|c|c|c|c|}
\hline $\begin{array}{c}\text { Day } \\
\text { Analyzed }\end{array}$ & $\begin{array}{l}\text { Weight of } \\
\text { Lithium } \\
\text { Taken } \\
\text { (mg) }\end{array}$ & $\begin{array}{c}\text { Instrument } \\
\text { Reading } \\
\text { ( } \mu \mathrm{g} \mathrm{Cl}\end{array}$ & $\begin{array}{c}\text { Carbon } \\
\text { Concentration } \\
(\mu \mathrm{g} / \mathrm{g})\end{array}$ \\
\hline & \multicolumn{2}{|c|}{ Origiriăl Litmium Hiydride Batch } & \\
\hline \multirow[t]{5}{*}{1} & 58.0 & 46 & $7 \dot{9} \dot{3}$ \\
\hline & 58.0 & 46 & 793 \\
\hline & 55.0 & 42 & 764 \\
\hline & 50.8 & 34 & 669 \\
\hline & 56.0 & 46 & 821 \\
\hline \multirow[t]{6}{*}{2} & 59.0 & 56 & 949 \\
\hline & 50.3 & 41 & 815 \\
\hline & 54.1 & 40 & 739 \\
\hline & 52.9 & 45 & 851 \\
\hline & 54.3 & 42 & 773 \\
\hline & 66.6 & 54 & 811 \\
\hline \multirow[t]{6}{*}{3} & 61.1 & 50 & 818 \\
\hline & 54.7 & 36 & 658 \\
\hline & 49.7 & 38 & 765 \\
\hline & 49.9 & 39 & 782 \\
\hline & \multicolumn{2}{|r|}{ Overall Mean } & 787 \\
\hline & Spiked Lit & n Hydride Balcli & \\
\hline \multirow[t]{4}{*}{1} & 55.6 & 66 & 1187 \\
\hline & 70.5 & 103 & 1461 \\
\hline & 82.2 & 99 & 1204 \\
\hline & 68.0 & 85 & 1250 \\
\hline \multirow[t]{6}{*}{2} & 69.9 & 79 & 1130 \\
\hline & 57.7 & 105 & $182 u^{(9)}$ \\
\hline & 66.1 & 75 & 1135 \\
\hline & $60 . ?$ & 83 & 1378 \\
\hline & 55.0 & 80 & 1455 \\
\hline & 66.2 & 83 & 1254 \\
\hline \multirow[t]{5}{*}{3} & 56.9 & 69 & 1213 \\
\hline & 51.8 & 62 & 1197 \\
\hline & $4 r .0$ & 62 & 1111 \\
\hline & 21.7 & 30 & 1382 \\
\hline & & Overall Mean & 1258 \\
\hline
\end{tabular}

(1) Outlier omitted.

\section{Comparison of Carbon Results from Hydride and Metals}

Carbon results from metal samples using similar LECO carbon instruments appeared to check much closer than results from lithium hydride samples. Two batches of metal turnings (from uranium metal and a uranium alloy) were analyzed repeatedly over periods of three and four months, respectively. Results are tabulated in Table 4. 
These metals likewise showed a significant difference between the results obtained on different days. The overall standard deviation was 8.8 micrograms of carbon per gram for the uranium metal and 13 micrograms of carbon per gram for the uranium alloy.

Upon comparison, the carbon results from the metal samples appear to be much more precise than the carbon results from the lithium hydride samples. However, a great difference exists in aliquant sizes. The metal samples were one gram whereas the lithium hydride aliquants averaged only 0.07 gram. With the small lithium hydride aliquant weights, a multiplication factor of 14 is required to convert results to a basis of one gram of sample. Examining results on the per-aliquant basis (Table 5), it is seen that the standard deviations experienced with lithium hydride are essentially the same as for the uranium metal samples and less than that for the uranium alloy samples. This comparison confirms the belief that the limiting factor on precision with lithium hydride samples is the capabilities of the method with the small sample size. The degree to which the instrument can be reproducibly set to standards is believed to account for the day-to-day variations. Twio aliquarls analyzed with the same settings on the instrument agree more closely than when analyzed separately with different standards settings being in the instrument.

\section{CONCLUSIONS}

Oplimization of the various factors affecting the combustion method has improved the precision and accuracy for the determination of carbon in lithium hydride. The revised procedure, as detailed in the Appendix, gives a. limit of error (0.95) for a single determination (at the 500 to 800 -ppm level) of $\pm 39 \%$ of the

Table 3

LONG-TERM RESULTS FROM LITHIUM HYDRIDE

\begin{tabular}{rrrrrr}
\hline $\begin{array}{c}\text { Aliquant Results } \\
(\mu \mathrm{g} \mathrm{C} / \mathrm{g})\end{array}$ & $\begin{array}{c}\text { Mean } \\
(\mu \mathrm{g} \mathrm{C} / \mathrm{g})\end{array}$ & $\begin{array}{c}\text { Aliquant Results } \\
(\mu \mathrm{g} \mathrm{C} / \mathrm{g})\end{array}$ & $\begin{array}{r}\text { Mean } \\
(\mu \mathrm{g} \mathrm{C} / \mathrm{g})\end{array}$ \\
\hline \multicolumn{5}{c}{ Batch 8} \\
405 & 392 & 398 & 281 & 168 & 224 \\
499 & 472 & 486 & 483 & 385 & 434 \\
451 & 497 & 474 & 481 & 585 & 533 \\
422 & 482 & 452 & 542 & 513 & 528 \\
556 & 495 & 526 & 553 & 514 & 534 \\
564 & 461 & 512 & 561 & 711 & 636 \\
568 & 483 & 526 & 487 & 411 & 449 \\
413 & 395 & 404 & 507 & 413 & 460 \\
480 & 383 & 432 & 425 & 500 & 462 \\
579 & 561 & 570 & 631 & 534 & 582 \\
468 & 357 & 412 & 423 & 399 & 411 \\
486 & 660 & 573 & 691 & 568 & 630 \\
556 & 384 & 470 & 530 & 557 & 544 \\
542 & 448 & 495 & 337 & 615 & 476 \\
615 & 574 & 594 & 536 & 550 & 543 \\
464 & 579 & 522 & 463 & 609 & 536 \\
604 & 502 & 553 & 529 & 496 & 512 \\
898 & 739 & 818 & 639 & 532 & 586 \\
538 & 521 & 530 & 782 & 746 & 764 \\
601 & 542 & 572 & 674 & 688 & 681 \\
423 & 350 & 386 & 658 & 717 & 688 \\
& Total Samples $=42$ & $0 v e r a l l$ & Mean $=522$ \\
& & & & &
\end{tabular}

Batch 9

\begin{tabular}{|c|c|c|c|c|c|}
\hline 887 & 839 & 863 & 675 & 636 & 656 \\
\hline 1135 & 1176 & 1156 & 860 & 826 & 843 \\
\hline 1114 & 928 & 1021 & 830 & 857 & 844 \\
\hline 905 & 942 & 924 & 858 & 699 & 778 \\
\hline 640 & 843 & 742 & 768 & 705 & 736 \\
\hline 991 & 908 & 950 & 839 & 727 & 783 \\
\hline 994 & 882 & 938 & 634 & 718 & 676 \\
\hline 910 & 943 & 926 & 724 & 734 & 729 \\
\hline 769 & 883 & 826 & 734 & 894 & 814 \\
\hline 824 & 962 & $89: 3$ & 778 & 754 & 766 \\
\hline 880 & 825 & 852 & 697 & 697 & 697 \\
\hline 838 & 977 & 908 & 1242 & 805 & 1024 \\
\hline 689 & 878 & 784 & 898 & 866 & 882 \\
\hline 1005 & 1003 & 1004 & 519 & 532 & 526 \\
\hline 936 & 844 & 890 & 802 & 681 & 742 \\
\hline 702 & 704 & 703 & 648 & 692 & 670 \\
\hline 801 & 812 & 806 & 973 & 785 & 879 \\
\hline 789 & 642 & 716 & 629 & 781 & 705 \\
\hline 629 & 630 & 630 & 609 & 690 & 650 \\
\hline 714 & 736 & 725 & 856 & 855 & 856 \\
\hline 738 & 718 & 728 & 657 & 568 & 612 \\
\hline 832 & 930 & 881 & 871 & 812 & 842 \\
\hline 812 & 715 & 764 & 845 & 724 & 784 \\
\hline 686 & 774 & 730 & 825 & 1086 & 956 \\
\hline 781 & 718 & 750 & 715 & 816 & 766 \\
\hline 791 & 681 & 736 & 669 & 610 & 640 \\
\hline 696 & 636 & 666 & & & \\
\hline \multicolumn{3}{|c|}{ Total Samples $=53$} & \multicolumn{3}{|c|}{ Overall Mean $=799$} \\
\hline
\end{tabular}


mean, compared to $\pm 94 \%$ of the mean for previous techniques. Analysis of lithium hydride samples spiked with lithium carbonate showed a recovery of $90 \%$ of the added carbon.

A range of 200 to 15000 micrograms of carbon per gram of lithium hydride appears practical, with poorer precision below 300 micrograms of carbon per gram. All materials used with the samples (such as the copper and iron, and the aluminum discl were used with the standards for setting the instrument. This arrangement compensated for any trace carbon present in the materials and equipment used. Compensation for the blank in this way plus the improved precision has eliminated the unreasonably high values sometimes obtained in previous analyses. Analyses in duplicate provided a more dependable result and also revealed any gross contamination of a sample aliquant.

The limits of precision appear to have been reached with the present instrument. Further improvement might be brought about by. a larger aliquant size in the event a suitable source for larger capsules is found. Combustion of a larger amount of lithium hydride possibly would bring the problem of greater attack on the combustion crucible; thus, once again, limiting the alıquant size.
Table 4

LONG-TERM CARBON RESULTS FROM METALS

\begin{tabular}{|c|c|c|c|c|c|c|}
\hline \multicolumn{2}{|c|}{$\begin{array}{l}\text { Aliquant Results } \\
\text { ( } \mu \mathrm{g} \mathrm{C} / \mathrm{g})\end{array}$} & \multirow{2}{*}{$\frac{\begin{array}{c}\text { Mean } \\
(\mu \mathrm{g} \mathrm{C} / \mathrm{g})\end{array}}{\text { Uran }}$} & \multicolumn{3}{|c|}{$\begin{array}{l}\text { Aliquant Results } \\
(\mu \mathrm{g} \mathrm{C} / \mathrm{g})\end{array}$} & \multirow{3}{*}{$\begin{array}{c}\begin{array}{c}\text { Mean } \\
(\mu \mathrm{g} \mathrm{C} / \mathrm{g})\end{array} \\
366\end{array}$} \\
\hline & & & & & & \\
\hline 379 & 383 & 381 & 366 & & 366 & \\
\hline 382 & 393 & 388 & 386 & & 391 & 388 \\
\hline 376 & 386 & 381 & 376 & & 386 & 381 \\
\hline 382 & 382 & 382 & 368 & & 372 & 370 \\
\hline 382 & 382 & 382 & 373 & & 364 & 368 \\
\hline 369 & 373 & 371 & 379 & & 371 & 375 \\
\hline 375 & 379 & 377 & 379 & & 377 & 378 \\
\hline 391 & $38 R$ & $39 n$ & 388 & & 374 & 381 \\
\hline 3991 & .381 & 386 & 377 & & 381 & 379 \\
\hline 372 & 380 & 376 & 373 & & 369 & 371 \\
\hline 386 & 386 & 386 & 382 & & 392 & 387 \\
\hline 397 & 404 & 400 & 372 & & 381 & 376 \\
\hline 380 & 403 & 392 & 377 & & 380 & 378 \\
\hline \multirow[t]{3}{*}{380} & 390 & 385 & 370 & & 376 & 373 \\
\hline & \multicolumn{2}{|c|}{ Total Samples $=28$} & \multicolumn{3}{|c|}{ Overall Mean $=380$} & \\
\hline & & \multicolumn{3}{|c|}{ Uranium Alloy } & & \\
\hline 52 & 37 & 44 & 56 & & 51 & 54 \\
\hline 54 & 56 & 55 & 58 & & 76 & 67 \\
\hline 68 & 57 & 62 & 62 & & 69 & 66 \\
\hline 57 & 56 & 56 & 87 & 78 & $52(1)$ & 72 \\
\hline 56 & 60 & 58 & 58 & & 60 & 59 \\
\hline 52 & 54 & 53 & 48 & & 46 & 47 \\
\hline 44 & 50 & 17 & & & & \\
\hline 66 & 67 & 66 & & & & \\
\hline 58 & 73 & 66 & & & & \\
\hline 60 & 59 & 60 & & & & \\
\hline 57 & 49 & 5.3 & & & & \\
\hline 101 & 87 & 94 & & & & \\
\hline \multirow[t]{2}{*}{58} & 58 & 58 & & & & \\
\hline & \multicolumn{2}{|c|}{ Total Samples $=19$} & \multicolumn{3}{|c|}{ Overall Mean $=60$} & \\
\hline
\end{tabular}

(1) Three aliquant results on this run.

Table 5

COMPARISON OF THE PRECISION OF CARBON ANALYSES OF LITHIUM HYDRIDE AND METAL SAMPLES

\begin{tabular}{|c|c|c|c|c|c|c|}
\hline \multirow[b]{2}{*}{$\begin{array}{c}\text { Material } \\
\text { Type }\end{array}$} & \multirow[b]{2}{*}{$\begin{array}{c}\text { Mean Carbon } \\
\text { Concentration } \\
(\mu \mathrm{g} \mathrm{C} / \mathrm{g})\end{array}$} & \multirow{2}{*}{$\begin{array}{c}\text { Average } \\
\text { Aliquant } \\
\text { Weight } \\
\text { (g) }\end{array}$} & \multicolumn{2}{|c|}{$\begin{array}{l}\text { Standard Deviation } \\
\text { Within Analyses } \\
\text { Based On }(\mu \mathrm{g})\end{array}$} & \multicolumn{2}{|c|}{$\begin{array}{c}\text { Overall Standard } \\
\text { Deviation } \\
\text { Based On }(\mu \mathrm{g})\end{array}$} \\
\hline & & & $\begin{array}{c}\text { One-Gram } \\
\text { Sample }\end{array}$ & $\begin{array}{l}\text { Average } \\
\text { Aliquant } \\
\text { Weight }\end{array}$ & $\begin{array}{c}\text { One-Gram } \\
\text { Sample }\end{array}$ & $\begin{array}{l}\text { Average } \\
\text { Aliquant } \\
\text { Weight }\end{array}$ \\
\hline LiH, Batch 8 & 522 & 0.07 & 69 & 4.8 & 116 & 8.1 \\
\hline LiH, Batch 9 & 799 & 0.07 & 83 & 5.8 & 135 & 9.4 \\
\hline Uranium Metal & 380 & 1.0 & 5.8 & 5.8 & 8.8 & 8.8 \\
\hline Uranium Alloy & 60 & 1.0 & 8.1 & 8.1 & 13 & 13.0 \\
\hline
\end{tabular}


The revised procedure is a fast and easy method for measuring the carbon content of lithium hydride with the accuracy and precision presently needed to identify samples with an unusual amount of carbon contamination. 


\section{ACKNOWLEDGEMENTS}

Much credit is due E. E. Johnson of the $Y-12$ Statistical Services Group for the guidance and interpretation of the statistical analysis of the results which were provided. J. H. Rowan of the Y-12 Development Division reviewed this report and offered helpful suggestions for content and expression. 


\section{APPENDIX \\ DETAILED REVISED PROCEDURE FOR DETERMINING LOW CARBON IN LITHIUM HYDRIDE OR DEUTERIDE}

\section{A. INTRODUCTION}

Determination of low amounts of carbon in lithium hydride or deuteride is made with the use of a LECO Low-Carbon Analyzer, Model 734-400. This apparatus consists primarily of a high-frequency induction furnace and an analyzer. The analyzer is composed of a gas chromatographic column, a thermal conductivity cell, an oven temperature controller, a computer section, and a digital voltmeter, timer, trap, heater, and power supply.

In this method, carbon is determined as follows: The sample and appropriate accelerators are placed in a crucible and heated in a helium atmosphere to release the hydrogen. Then, the crucible containing the decomposed sample is ignited in a flow of purified oxygen. The carbon in the sample is converted to $\mathrm{CO}_{2}$ and a small amount of $\mathrm{CO}$, then these gases and other combustion products and free oxygen are passed through a dust trap to remove any dust and through a manganese dioxide trap (if necessary) to remove any sulfur oxides. The $\mathrm{CO}_{2}+\mathrm{CO}+\mathrm{O}_{2}$ mixture is passed through a catalytic heater (copper oxide or manganese dioxide) to convert the $\mathrm{CO}$ to $\mathrm{CO}_{2}$. The $\mathrm{CO}_{2}+\mathrm{O}_{2}$ mixture is then passed into the molecular sieve trap. When the trap is heated, the released $\mathrm{CO}_{2}$ is swept through a silica-gel column to the thermal conductivity measuring cell which is part of a modified Wheatstone bridge. The imbalance caused in the bridge circuit by the $\mathrm{CO}_{2}$ is integrated and read directly on the digital integrator as micrograms of carbon.

Appropriate blanks and standards are analyzed during each shift that samples are analyzed to verify the calibration data. National Bureau of Standards steel samples are used as the control standards. High and low amounts of carbon are obtained by varying the weight of the standard materials. The weight of the standard taken should be approximately the same as the weight of the aliquant used in the analysis, since the heat generated by the induction furnace is dependant on the size of the aliquant.

Carbon may be determined by this procedure in the range of 200 to 15000 micrograms per sample aliquant. The limit of error at the $95 \%$ confidence level of a single measurement of carbon in lithium hydride is \pm 30 to $50 \%$ relative at the 400 to 1500-microgram level.

\section{B. REAGENTS}

The following reagents are employed:

Ascarite (sodium hydrate asbestos absorbant), 8 to 20 mesh.

Copper metal, chemically pure, granılar (accelerator) LECO 501 263.

Helium gas, reagent grade. 
Iron powder, Sintrex, (c) low carbon.

Iron standard [NBS 166b (190 ppm C) and NBS 32e (4090 ppm)].

Magnesium perchlorate, anhydrous, reagent grade.

Manganese dioxide, powder, reagent grade.

Molecular sieve, LECO Trap Material 501-197.

Oxygen gas, reagent grade.

Sulfuric acid, concentrated (95\%), reagent, ACS.

Silica gel, LECO Column Material 501-198.

\section{EQUIPMENT}

The following items of equipment are utilized:

Analyzer, LECO Low Carbon, Model 734-400.

Balance, analytical.

Crucibles, combustion, high temperature, LECO 528-035.

Crucible cover, porous, LECO 528-042.

Desiccator with cover, large size.

Disc, aluminum, cut from $0.038-\mathrm{mm}(11 / 2-\mathrm{mil})$ foil, to fit top of crucible.

Dry Box, argon atmosphere, $<50$ ppm moisture.

Flowmeter tor helıum flow-through furnace.

rorceps.

Furnace, muffle.

Granular sand, prepared as in Step D.5.c.

Scoop, sized to hold $0.70-0.75 \mathrm{~g}$ of iron powder or $1.0 \mathrm{~g}$ of copper metal, cylindrical, approximately $6 \mathrm{~mm} / \mathrm{D}$ and $7 \mathrm{~mm}$ deep.

(c) Manufactured by the Easton Metal Powder Company. 
Spatula.

Switching system of electrically operated valves to change from a helium to an oxygen flow.

Timer, supplementary, connected to add two minutes to the combustion time.

Tin capsule, LECO 501-59.

Tongs, long form.

Vials with caps, plastic.

Wool, glass fiber.

\section{FUNCTIONS AND PREPARATION OF EQUIPMENT}

\section{Furnace Controls (see Figure A-1)}

a. Filament Switch. Controls the power to the filament or mercury of the rectifier tubes. If the tubes are kept "on", even when the instrument is not is use, the mercury in the tubes will stay vaporized and the tubes will remain in the "ready" condition for immediate use. Also, life of the tubes is usually extended when the filament switch is left on overnight. If the instrument power and filament have been turned off prior to use, a few minutes should be allowed for tube warm up. after the filament switch has been turned on, before turning on the induction coil.

b. High-Voltage Switch. Energizes the induction coil. A variable transformer controls the amount of power to the induction coil.

\section{Analyzer Controls (see Figure A-2)}

a. Power Switch Indicator. (located on the lower right side of the right panel). Controls the power to the oven unit, timer, trap heater, integrators, and thermal conductivity cell. The switch should be left at "AC on" at all times except when maintenance is required. Press this switch to turn the analyzer on or off. When the analyzer is at the "on" position, this indicator will glow red.

b. Heater Indicator. When the heater in the oven has electric power applied to it, this indicator will glow white. This indicator will turn on and off in normal operation since the temperature is thermostatically controlled.

c. Blank Switch/Indicator. Press this switch to insert or remove the blank correction. The indicator will glow green when the blank correction is inserted.

d. Clamp Switch/Indicator. Press this switch to fasten or unfasten the digital voltmeter clamp. The indicator will glow yellow when the clamp is fastened. 


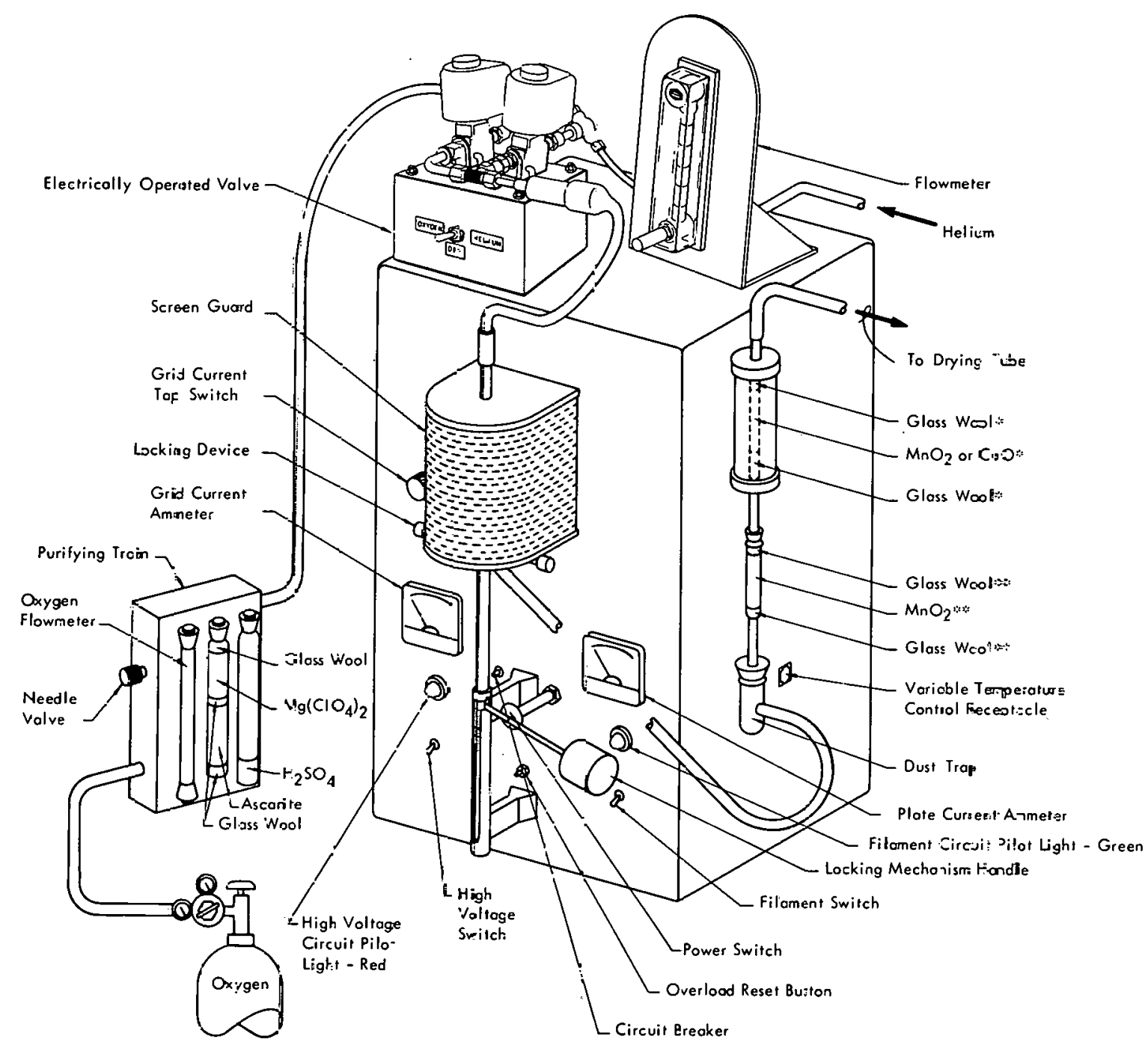

Figure A-1. CARBON-IN-LITHAUG HYDRIDE ANALYZER. (Induction Furnace Section) 


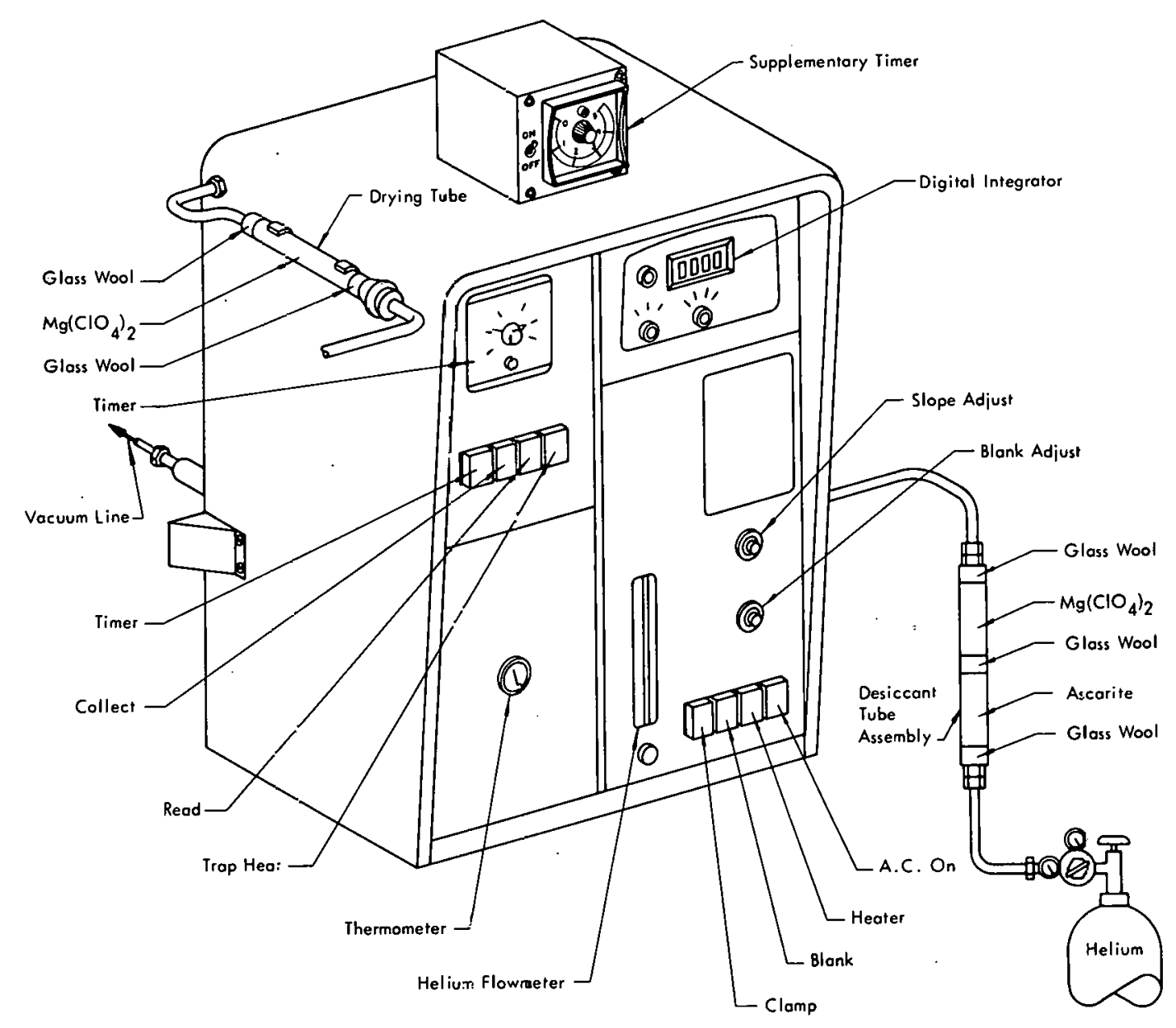

Figure A-2. CARBON-IN-LITHIUM HYDRIDE ANALYZER. (Carbon Measurement Section) 
When the clamp is unfastened, the digital voltmeter will indicate the output of the integrator continuously.

e. Timer Switch/Indicator. Press to turn the timer on or off. When the timer is running, this indicator will glow red. When the timer is off, power cannot be applied to the trap heater, trap blower, collect/analyze valve, or furnace.

f. Trap-Heat Indicator. When the trap is heated to a temperature greater than the ambient temperature, this indicator will glow yellow. The trap temperature must be reduced to near room temperature before it can collect a new gas sample. This condition is indicated when the trap-heat indicator is off. The trap-heat indicator operates whether or not the timer is running.

g. Collect Indicator. Whenever the transfer valve is in the "collect" position, this indicator will glow yellow. This indicator will not glow unless the timer is running.

h. Read Indicator. Whenever the cycle is complete and the final result appears on the digital integrator, this indicator will glow green, but it will not glow unless the cycle is completed.

i. Cycle Timer. Controls the collection, elution, and analysis sequences of the carbon analyzer. The cycle timer automatically collects or analyzes the sample, turns on the trap heat for approximately 15 seconds, integrates the $\mathrm{CO}_{2}$ peak, then unclamps and clamps the digital vultureler.

i. Thermometer. Indicates the temperature of the chromatuyraphic column and oven in whith it is contained. The gage should indicate a temperature of abuut $46^{\circ} \mathrm{C}$ or at least a temperature abuve llie anbient room temperaturo. Slight changes in room temperature, therefore, will have litlle effect on the retention-time properties of the column for which the timer and integrator are preset.

k. Valve and Flowmeter, Analyzer Helium Flow. The analyzer helium flowmeter should indicate a flow of 40 with a line pressure of 20 psii. By turniny llie kinub below the flowmeter, the flow may be adjusted to the desired reading. The exact flow rate is given by the manufacturer.

I. Digital Integrator. Integrates the detector signal during the analyzing cycle when $\mathrm{CO}_{2}$ is eluted through the detector. Results are displayed as micrograms of carbon.

m. Slope Adjust. A potentiometer used to adjust the reading of the high standard to the proper setting.

n. Blank Adjust. A potentiometer used to adjust the reading of the low standard to the proper setting.

\section{Purifying Train (see Figure A-1)}


a. Sulfuric Acid Tower. This acid should be changed whenever it becomes dark brown or black with impurities.

b. Carbon Dioxide Absorber Tower. The magnesium perchlorate and Ascarite should be changed when depleted. (Depletion is indicated when the magnesium "perchlorate appears moist and caked and when an inch of the Ascarite appears white.)

c. Oxygen Flowmeter. The oxygen flow through the furnace should be set at two liters per minute, with a line pressure of 1 psi.

\section{Impurity Traps}

The traps for impurities and dust are as follows:

a. Dust Trap. A glass bulb containing a rubber stopper and glass diaphragm covered with cloth are used to trap dust particles which are contained in the gas flow from the furnace.

b. Sulfur Trap. If necessary, a glass cylinder containing manganese dioxide is used to trap sulfur gases which would interfere with the analysis of carbon.

c. Heated Oxidizing Trap. A glass tube containing copper oxide or manganese dioxide, heated by an electric heating element, is used to convert $\mathrm{CO}$ to $\mathrm{CO}_{2}$.

d. Drying Trap. A glass tube containing magnesium perchlorate is used to trap water which would interfere with the analysis of carbon.

e. Desiccant Trap. A metal cyclinder is filled with Ascarite and magnesium perchlorate and placed in the helium gas flow line to remove such impurities as carbon dioxide and water.

\section{Vapor Exhaust}

If desired, an exhaust duct or vacuum hose may be provided at the vent from the analyzer section to carry away excess oxygen and/or vapors.

\section{Preparation of Crucibles and Covers}

a. Ignite the crucibles and covers in a muffle furnace at $1000^{\circ} \mathrm{C}$ for two hours.

b. Remove the crucibles and covers from the muffle furnace with tongs and store in a desiccator until ready to use. Handle the ignited crucibles and covers only with tongs.

c. Prepare granular sand for covering the bottom of the crucibles by grinding porous crucible covers in a rotary grinder (eg, a Bleuler mill) for approximately two minutes. Trace carbon in the sand is burned away by ignition at $1000^{\circ} \mathrm{C}$ for two hours or more. 
d. Clean the aluminum-foil discs with Freon 113 solvent in an ultrasonic bath. Rinse with alcohol and dry in a heated argon stream.

\section{E. INSTRUMENT CALIBRATION}

When the instrument startup is completed, as described in Step F.1-Daily Instrument Startup-continue with the calibration as follows:

\section{Conditioner Samples}

a. Prepare two conditioner samples by duding two scoops of copper metal acceleratoor and one scoup of iron powder accelerator to the rrucihles.

b. React each conditioner sample, as described in Step F.4-Sample Combustion.

\section{Standards}

a. Weigh, to the nearest $0.1 \mathrm{mg}$, approximately $0.1 \mathrm{~g}$ of a low-iron standard (eg, NBS Steel Sample 166b). Transfer to a combustion crucible containing two scoops of prepared sand, one scoop of iron powder accelerator, and two scoops of copper metal accelerator. Cover the crucible with an aluminum disc and porous cover.

b. React the low-standard aliquant, as described in Steps F.4.a through F.4.c. As soon as the reading beglis iu clialige on the digital voltmeter, turn off the timer by pressing the TIMEF Indicator button. Adjust the BLANK ADJUST jutentiomcter until the exact carbon value of the standard aliquant $(19 \mu \mathrm{g}$ carbon for $0.1 \mathrm{~g}$ NBS $166 \mathrm{~b}$ ) appears on the digital voltmeter. Turn on the timer by pressing the TIMER Indicator button and allow the cycle to continue to completion.

c. Repeat steps a and $b$ with a high-standard aliquant, setting the SLOPE ADJUST potentiometer to bring the exact carbon value of the standard aliquant $(409 \mu \mathrm{g}$ carbon for $0.1 \mathrm{~g} \mathrm{NBS} 32 \mathrm{e}$ ) on the digital voltmeter.

d. Repeat the standardization steps with both low and high standards. The low staridard shuuld eheck within $\pm 3 \mu \mathrm{g}$ carbon; the high standard should check within $\pm 10 \mu \mathrm{g}$ cerbon.

\section{F. PROCEDURE}

\section{Daily Instrument Startup}

a. Check the impurity traps; and, if required, proceed as follows:

(1) Clean the dust trap and replace the cloth.

(2) Repack the drying trap with fresh magnesium perchlorate. 
(3) Repack the heated oxidizing trap with fresh manganese dioxide or copper oxide.

b. Check the equipment to ascertain that:

(1) The electrical power to the furnace, the analyzer, and the supplementary timer is on.

(2) The trap heater on the furnace is heating.

(3) The purifying train flowmeter is working properly, good reagents are in the $\mathrm{CO}_{2}$ absorber tower, and clean sulfuric acid is in the acid tower.

(4) The variable temperature control is at the proper setting.

(5) There are sufficient crucibles, covers, and reagents for the shift operation.

(6) The oxygen and helium supplies are sufficient for the shift operation.

c. Turn on the helium gas pressure valve and set the regulator to 10 to 20 pounds pressure on the helium gage. The analyzer flowmeter should read " 40 ", or as given by the manufacturer.

d. Turn on the oxygen gas pressure valve and set the regulator to one pound pressure on the oxygen gage. The purifying train flowmeter should read two liters per minute.

e. Allow the furnace and analyzer to warm up for 30 minutes before use.

f. The indicator lights should be lighted in the "on" position as follows:

(1) Furnace: High Voltage (red) and Filament (green).

(2) Arlalyzer: Timer (red), AC On (red), Blank (green), and Clamp (yellow).

g. Set the automatic timer of the analyzer for four minutes (two minutes combustion and two minutes analyzer time).

h. Set the supplementary timer for two minutes.

i. Calibrate the instrument, as described in Step E-INSTRUMENT CALIBRATION-before analyzing the unknown samples.

\section{Sample Preparation}

a. Weigh the tin capsule to the nearest $0.1 \mathrm{mg}$. Record the weight under "sample tare" on the work card. Place the capsule in a plastic vial labeled with the requisition number and bin number of the sample. 
b. Transfer the plastic vial containing the tared capsule to the argon-atmosphere dry box.

c. Remove the capsule from the vial and fill it with the LiH or LiD sample. Close the capsule by crimping with forceps. Return the filled capsule to the vial, cap the vial, and remove the vial from the dry box.

d. Remove the capsule from the vial and weigh the capsule to the nearest $0.1 \mathrm{mg}$. Record the weight under "sample gross" on the work card. Determine the net weight of the sample aliquant by difference. Store the capsule in the vial in a dry box until ready for the combustion step.

e. Transter the capsule to a crucible containing two scoops of prepared sand, one scoop of iron powder accelerator, and two scoops of copper metal accélerrátór. Cover the crucible with the aluminum disc and norous crusihle rnver.

\section{Sample Decomposition}

a. Switch the furnace sweep gas to helium. A satisfactory helium flow rate is 1.0 scfh on a flowmeter calibrated for air.

b. Lower the pedestal on the furnace, position the crucible containing the sample onto the pedestal, raise the pedestal, and lock the pedestal in place.

c. Allow one-half minute for the helium to flush the system and then turn on the furnace.

d. Let the sample decompose under heat, driving off the hydrogen. Decomposition is complete, as indicated by a red glow ( 2 to 3 minutes). The plate current should rise to 150 to $200 \mathrm{~mA}$.

\section{Sample Combustion}

a. Set the timer of the LECO analyzer unit to four minutes if not previously set. Start the two-minute supplementary timer.

b. Switch the furnace sweep gas to oxygen.

c. Permit the reaction to complete a four-minute burning time. The plate current should rise to $350 \mathrm{~mA}$ or more to insure complete combustion.

d. When the readout indicator light comes on (green), record the carbori reading as it appears on the digital integrator.

e. Lower the furnace pedestal, remove the crucible, and raise the pedestal into place to close the furnace. 


\section{G. CALCULATIONS}

Calculate the carbon in a lithium hydride or lithium deuteride sample using the following equiation:

$$
\therefore \because \therefore \quad \therefore \quad \therefore \quad \therefore \quad \therefore \quad \therefore \quad \therefore \quad \text { C }
$$

where

man

C represents the carbon content in the sample in micrograms of carbon per gram of sample,

$R$ the recorded carbon reading from the digital integrator, and

$W$ the net weight of the sample aliquant in grams. 


\section{Distribution}

Energy Research and Development Administration - Óak Ridge

Yaggi, W. J./Googin, J. M.

$Y-12$ Central Files (5)

Hickman, H. D.

Leed, R. E.

Zachry, D. S., Jr

$Y-12$ Central Files (master copy)

$Y-12$ Central Files (route copy)

$Y-12$ Central Files ( $Y-12 R C$ )

Zerby, C. D.

Oak Ridge Gaseous Diffusion Plant

Barringer, R. E. (6)

Barton, J. C.

Paducah Gaseous Diffusion Plant

Stief, S. S.

Wilcox. W. d.. Jr

Oak Ridge Y-12 Plant

Andrew, R. E.

Bernander, N. K.

Briscoe, O.W.

Burditt, R. B.

Burkhart, L. E.

Charles, J.W.

Durham, R. B. (2)

Fraser, R. J.

Freels, W. A., Jr

Harvey, T. R.

Johnson, E. E.

Jones, $\Gamma$. W.

kahl, k. G.

Keith, A.

Kite, H. T.

Lundin, M. I.

McLendon, J. D.

Mills, J. M., Jr

Montgomery, C. D.

Fhillips, L. R.

Rúvaari, J. H. (10)

Schreyer, J. M.

Smith, H. F., Ir

Smith, R. D.

Tewes, W. E.

Thomason, J. C.

Thornton, R. E. (3)

Weathersby, W. E.

In addition, this report is distributed in accordance with the category UC-4, Chemistry, as given in the USERDA Standard Distribution Lists for Unclassified Scientific and Technical Reports, TID-4500. 